\title{
REVIEW
}

\section{Selenium and endocrine systems}

\author{
Geoffrey J Beckett and John R Arthur ${ }^{1}$ \\ Clinical Biochemistry, University of Edinburgh, The Royal Infirmary of Edinburgh, 51 Little France Crescent, Little France, Edinburgh EH16 4SA, Scotland, UK \\ ${ }^{1}$ Rowett Research Institute, Bucksburn, Aberdeen AB21 9SB, Scotland, UK \\ (Requests for offprints should be addressed to G J Beckett; Email: G.J.Beckett@ed.ac.uk)
}

\begin{abstract}
The trace element selenium (Se) is capable of exerting multiple actions on endocrine systems by modifying the expression of at least 30 selenoproteins, many of which have clearly defined functions. Well-characterized selenoenzymes are the families of glutathione peroxidases (GPXs), thioredoxin reductases (TRs) and iodothyronine deiodinases (Ds). These selenoenzymes are capable of modifying cell function by acting as antioxidants and modifying redox status and thyroid hormone metabolism. Se is also involved in cell growth, apoptosis and modifying the action of cell signalling systems and transcription factors. During thyroid hormone synthesis GPX1, GPX3 and TR1 are up-regulated, providing the thyrocytes with considerable protection from peroxidative damage. Thyroidal D1 in rats and both D1 and D2 in humans are also up-regulated to increase the production of bioactive 3,5,3'-tri-iodothyronine (T3). In the basal state, GPX3 is secreted into the follicular lumen where it may down-
\end{abstract}

regulate thyroid hormone synthesis by decreasing hydrogen peroxide concentrations. The deiodinases are present in most tissues and provide a mechanism whereby individual tissues may control their exposure to T3. Se is also able to modify the immune response in patients with autoimmune thyroiditis. Low sperm production and poor sperm quality are consistent features of Se-deficient animals. The pivotal link between Se, sperm quality and male fertility is GPX4 since the enzyme is essential to allow the production of the correct architecture of the midpiece of spermatozoa. Se also has insulin-mimetic properties, an effect that is probably brought about by stimulating the tyrosine kinases involved in the insulin signalling cascade. Furthermore, in the diabetic rat, Se not only restores glycaemic control but it also prevents or alleviates the adverse effects that diabetes has on cardiac, renal and platelet function.

Journal of Endocrinology (2005) 184, 455-465

\section{Introduction}

The biological roles ascribed to selenium (Se) include the prevention of cancer (Combs \& Lu 2001) cardiovascular disease (Rayman 2002, Beckett et al. 2004) and viral mutation (Beck 2001). In addition the trace element is essential for optimal endocrine and immune function and moderating the inflammatory response (McKenzie et al. 2002b, Arthur et al. 2003).

These biological actions are mediated in most cases through the expression of at least 30 selenoproteins coded by 25 selenoprotein genes in humans (Kryukov et al. 2003). The importance of Se to endocrine systems is highlighted by the fact that many endocrine tissues have evolved mechanisms to maintain relatively high concentrations of Se even when there is severe dietary deficiency. This review will focus on the various mechanisms by which Se may modify thyroid function, fertility and glucose homeostasis.
The current recommended dietary intake of $\mathrm{Se}$ in humans is between 55 and $75 \mu \mathrm{g}$ per day (Rayman 2000). These amounts are based on the Se intake that maximally induces the activity of glutathione peroxidase (GPX) in plasma or erythrocytes. The anticancer properties of Se operate at intakes of the order of $200 \mu \mathrm{g} /$ day, suggesting that a re-appraisal of dietary Se intake may be useful. Many areas of the globe including the UK have Se intakes that are significantly below the current recommended intake, leading to sub-maximal expression of GPX and other selenoproteins in blood and tissues (Brown et al. 2000, Rayman 2002).

\section{The selenoproteins}

The selenoproteins incorporate Se co-translationally as a selenocysteine residue that is fully ionized at physiological $\mathrm{pH}$ and acts as a very efficient redox catalyst. Of the up to 30 selenoproteins that have been characterized or 
Table 1 Mammalian selenoproteins and their functions

\begin{tabular}{ll} 
& Proposed function \\
\cline { 2 - 2 } $\begin{array}{l}\text { Selenoprotein } \\
\text { Glutathione peroxidases (GPXs) }\end{array}$ & \\
GPX1 & Antioxidant in cell cytosol; Selenium store? \\
GPX2 & $\begin{array}{l}\text { Antioxidant in Gl tract } \\
\text { GPX3 }\end{array}$ \\
GPX4 & Antioxidant in extracellular space and plasma \\
GPX5 & $\begin{array}{l}\text { Membrane antioxidant; structural protein in sperm; } \\
\text { apoptosis? }\end{array}$ \\
GPX6 & Unknown \\
Thioredoxin reductase (TRs) & GPX1 homologue? \\
& $\begin{array}{l}\text { Multiple roles including dithiol-disulphide oxoreductase } \\
\text { Detoxifies peroxides, reduces thioredoxin } \\
\text { (control of cell growth); maintains redox state of }\end{array}$ \\
TR1 & transcription factors \\
TR2 & Mainly cystosolic, ubiquitous \\
TR3 & Expressed by testes \\
lodothyronine deiodinases & Mitochondrial, ubiquitous \\
Type D1 and D2 & Converts thyroxine (T4) to \\
Type D1 and D3 & bioactive 3,5,3'-tri-iodothyronine (T3) \\
Selenoprotein P & Converts thyroxine (T4) to bioinactive 3', 3', 5' reverse T3 \\
Selenoprotein W & Selenium-transport protein. Antioxidant on endothelium \\
Selenophosphate synthetase & Synthesis of selenophosphate for selenoprotein synthesis. \\
\hline
\end{tabular}
(SPS2)

15 kDa Selenoprotein (Sep 15)

H, I, K, M, N, O, R, S, T, V

$\mathrm{Gl}$, gastrointestinal.
Protects against cancer?

Role largely unknown identified bioinformatically (Table 1), six are GPXs, three are iodothyronine deiodinases (Ds) and three are thioredoxin reductases (TRs; Kryukov et al. 2003). Selenoprotein $\mathrm{P}$ is quantitatively the major selenoprotein in plasma and has both antioxidant and transport roles (Burk et al. 2003, Hill et al. 2003, Mostert et al. 2003). Thus Se can influence at least three broad areas of cell biochemistry, namely antioxidant function, redox status and thyroid hormone metabolism.

\section{TRs}

The TRs, with thioredoxin as a substrate and NADPH as a cofactor, form a powerful dithiol-disulphide oxidoreductase system that regulates the cellular redox state of cells and may also protect against oxidative stress (Holmgren 2001, Kryukov et al. 2003). The system is also involved in many diverse cellular functions including cell signalling, regulation of cell growth and inhibition of apoptosis (Saitoh et al. 1998, Rundlof \& Arner 2004). A range of diseases in humans are suspected to be related to the activity of TR and the enzyme has become a major target for the development of therapeutic drugs (Becker et al. 2000, Gromer et al. 2004).

\section{GPXs}

At least six mammalian GPX isoenzymes have been described (Table 1). Cytosolic enzyme (GPX1) is expressed by all cells types in mammals. Extracellular GPX (GPX3) is a secreted glycoprotein that is the second most abundant selenoprotein in plasma while phospholipid hydroperoxide GPX (GPX4) can specifically reduce phospholipid hydroperoxides (Imai \& Nakagawa 2003) and may be involved in moderating apoptotic cell death (Nomura et al. 2001) and sperm maturation.

\section{Thyroid hormone deiodinases}

Three iodothyroinine deiodinases (D1, D2 and D3) have been identified. All are integral membrane proteins of 29-33 kDa, sharing 50\% sequence identity. Each has a selenocysteine residue at the active centre that confers the high catalytic activity of the enzymes. The deiodinases 


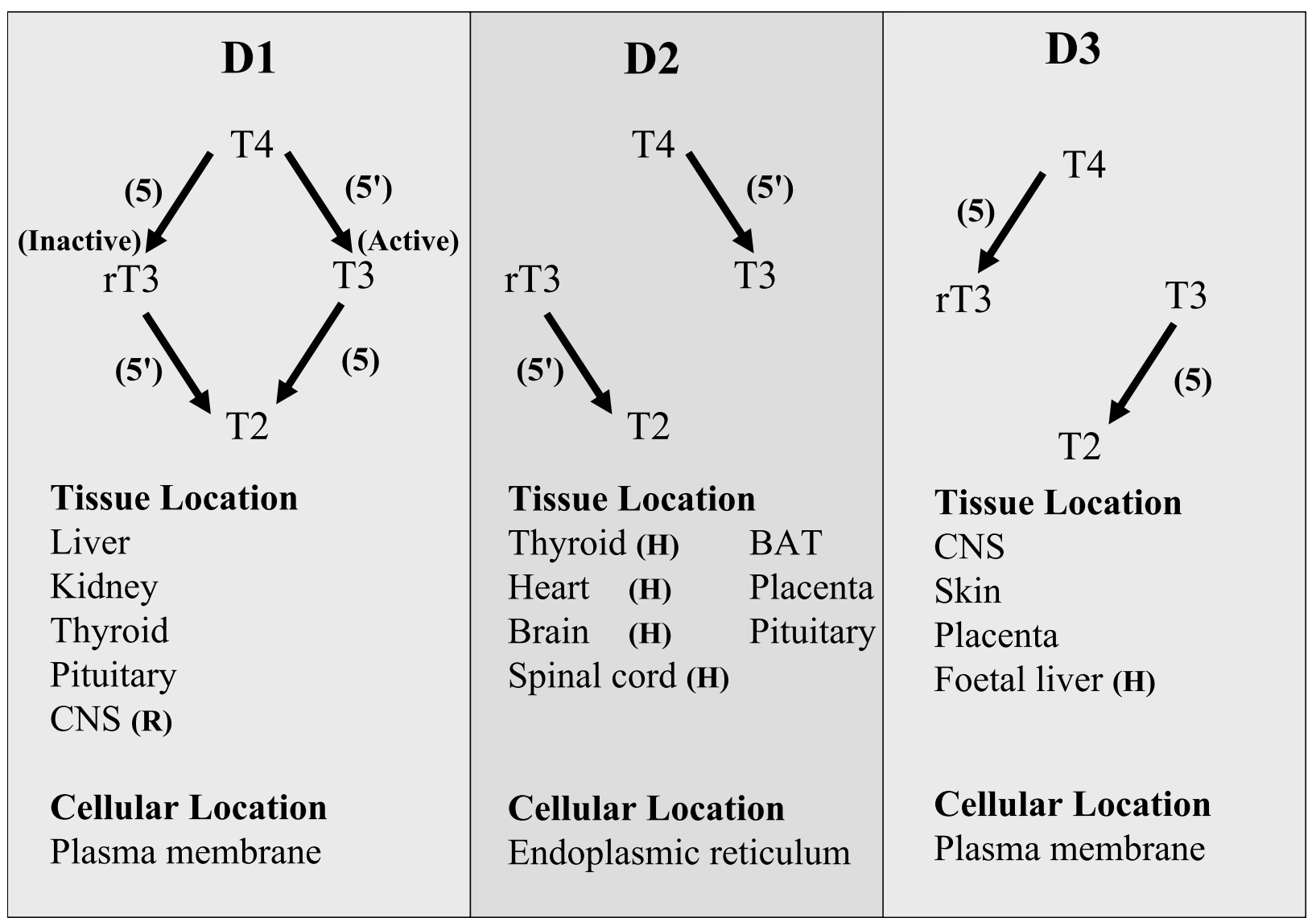

Figure 1 Characteristics of the iodothyronine deiodinases. T3 sulphate is also a substrate for 5-deiodination by D1. CNS, central nervous system; BAT, brown adipose tissue; T2 3,3'-di-iodothyronine; $(\mathrm{R})$, rat not human; $(\mathrm{H})$, human not rat.

have differing substrate specificities and tissue distribution (Bianco et al. 2002). The enzymes can catalyse the removal of iodine from the 5 or $5^{\prime}$ positions of iodothyronine substrates and in doing so have an important regulatory role in the activation and inactivation of the thyroid hormones in all tissues (Fig. 1).

Recently details of the protein structure of the deiodinases has become available. The extra-membrane portion of the deiodinases belongs to the thioredoxin-fold superfamily, a superfamily that also includes the GPXs. Furthermore, a large deiodinase region embedded in the thioredoxin fold shares strong similarities with the active site of iduronidase, a member of the clan GH-A-fold glycoside hydrolases. The substrates for the deiodinases (iodothyronines such as thyroxine (T4), reverse triiodothyronine (rT3) and 3,5,3'-tri-iodothyronine (T3)) and substrates for the iduronidase (sulphated $\alpha$-L-iduronic acid) are structurally similar, having O-linked hexagonal rings substituted with bulky groups lying ortho to the linker. It would thus appear that the deiodinases have iduronidase-like sequences embedded in the selenocyteine-containing thioredoxin fold that are critical for iodothyronine binding. The predicted protein structure of the deiodinases together with site-directed mutagenesis experiments have allowed the elucidation of some of the critical amino acids that are responsible for the differences in substrate specificity and enzyme kinetics observed between D1, D2 and D3 (Callebaut et al. 2003).

The deiodinases show marked tissue- and time-specific expression during the foetal period and may be important regulators of this maturation process by modifying the supply of T3 to T3-responsive genes (Hume et al. 2001, Kester et al. 2004). However, the ontogeny of the deiodinases and their tissue distribution is quite different in rats than humans, thus data obtained from rat models cannot always be appropriately applied to humans.

\section{Regulation of selenoprotein expression}

The predominant control of selenoprotein expression is Se supply with a strict hierarchy of selenoprotein expression 
when Se supply is limited. Endocrine tissues are well adapted to maintaining selenoprotein expression in Se deficiency and within any single tissue the expression of the deiodinases, GPX4 and TRs is maintained at the expense of GPX1, which is quickly lost (Behne et al. 1988, Bermano et al. 1995, 1996, Crosley et al. 2003). Oxidative stress induces TR1 and GPX (Sun et al. 1999) and isothiocyanates such as sulforaphane induce TR1 (Zhang et al. 2003). Activation of second-messenger pathways also modifies the expression of specific selenoproteins in a tissue-specific manner (Beech et al. 1995, Howie et al. 1995, 1998, Anema et al. 1999).

\section{Se and thyroid function}

The thyroid contains more Se per gram of tissue than any other organ (Dickson \& Tomlinson 1967) and Se, like iodine, is essential for normal thyroid function and thyroid hormone homeostasis. Labelling cultured human thyrocytes with $\left[{ }^{75} \mathrm{Se}\right]$ selenite reveals numerous selenoproteins with TRs and GPXs predominating (Fig. 2).

\section{Thyroid hormone synthesis}

Synthesis of thyroid hormone requires iodination of tyrosyl residues on thyroglobulin which is stored in the lumen of the thyroid follicle. This iodination is catalysed by thyroid peroxidase (TPO) and requires the generation of high $\mathrm{H}_{2} \mathrm{O}_{2}$ concentrations which are potentially harmful to the thyrocyte. The generation of $\mathrm{H}_{2} \mathrm{O}_{2}$ appears to be the rate-limiting step in thyroid hormone synthesis and is regulated through the action of thyroid-stimulating hormone (TSH) via a complex network of interacting, second-messenger systems (Corvilain et al. 1991, 1994, Raspe et al. 1991, Kimura et al. 1995). The iodination of thyroglobulin and generation of $\mathrm{H}_{2} \mathrm{O}_{2}$ takes place on the luminal surface of the apical membrane of the thyrocyte (Fig. 3). This organization allows the $\mathrm{H}_{2} \mathrm{O}_{2}$ formed on the surface of the thryocyte to be made readily available for iodination reactions, while any harmful $\mathrm{H}_{2} \mathrm{O}_{2}$ that diffuses into the thryocyte can be degraded by the intracellular GPX, TR and catalase systems (Ekholm \& Bjorkman 1997).

GPX3 as a potential regulator of thyroidal hormone production

The thyrocyte is capable of synthesizing and secreting GPX3 in a controlled manner. In basal conditions, cultured human thyrocytes secrete GPX3 and this secretion is prevented by the co-addition of the calcium ionophore A23187 and phobol ester (PMA), known stimulators of $\mathrm{H}_{2} \mathrm{O}_{2}$ production (Howie et al. 1995). This raises the intriguing possibility that GPX3 may provide an additional mechanism for controlling thyroid hormone synthesis through regulating the concentration of $\mathrm{H}_{2} \mathrm{O}_{2}$ in the follicular lumen. Thus when increased thyroid hormone production is signalled through the TSH receptor, increased synthesis of $\mathrm{H}_{2} \mathrm{O}_{2}$ at the apical membrane is accompanied by impaired secretion of GPX3 and thus diminished degradation of the peroxide. These concurrent changes would have the effect of amplifying the concentration of $\mathrm{H}_{2} \mathrm{O}_{2}$ available for iodination of thyroglobulin. When thyroid hormone synthesis is not strongly signalled, thyroid hormone production would be prevented both by diminished $\mathrm{H}_{2} \mathrm{O}_{2}$ synthesis and by active secretion of GPX3 across the apical membrane that would promote degradation of $\mathrm{H}_{2} \mathrm{O}_{2}$ produced in the basal state.

\section{Se as an antioxidant in the thyroid}

The thyrocyte is continually exposed to potentially toxic concentrations of $\mathrm{H}_{2} \mathrm{O}_{2}$ and lipid hydroperoxides. The cytotoxic effects of $\mathrm{H}_{2} \mathrm{O}_{2}$ on thyroid cells include caspase3 -dependent apoptosis that occurs at $\mathrm{H}_{2} \mathrm{O}_{2}$ concentrations that are insufficient to induce necrosis. In Se deficiency the apoptotic response to $\mathrm{H}_{2} \mathrm{O}_{2}$ is increased (Demelash et al. 2004). When Se intake is adequate the intracellular GPX and TR systems protect the thyrocyte from these peroxides. Furthermore, in iodine deficiency or Grave's disease, where hyperstimulation of the TSH receptor signals increased $\mathrm{H}_{2} \mathrm{O}_{2}$ production, activation of the calcium-phosphoinositol cascade stimulates GPX1 production and particularly TR1 (Fig. 2; Howie et al. 1998) thus providing an up-regulation of antioxidant protection (Fig. 3).

\section{Se as a regulator of $T 3$ production}

The deiodinase D1 is the major isoform in liver, kidney, thyroid and pituitary. It can catalyse 5 or $5^{\prime}-$ monodeiodination and thus can convert $\mathrm{T} 4$ to the inactive metabolite rT3 or the active isomer T3. The important physiological roles of D1 include providing an important source of plasma T3 and degrading rT3 and T3 sulphate.

There are species-specific differences in the expression of D2. In rats, D2 is predominantly expressed in brain, brown adipose tissue and pituitary with little or no expression being found in thyroid, skeletal muscle or heart. In humans, Northern blotting or activity measurements suggest that D2 expression occurs in thyroid, heart, brain, spinal cord, skeletal muscle, placenta, pituitary and keratinocytes and to some extent in kidney and pancreas. D2 can only perform $5^{\prime}$-deiodination reactions and the enzyme has a short half-life $(<1 \mathrm{~h})$, which is controlled by ubiquitination. Physiologically, D2 provides an intracellular source of $\mathrm{T} 3$ to specific tissues and, particularly in humans, it also appears to provide a significant source of plasma T3. Among its other physiological roles, D2 is critical for regulating brain development, TSH secretion in the pituitary and adaptive thermogenesis in brown 


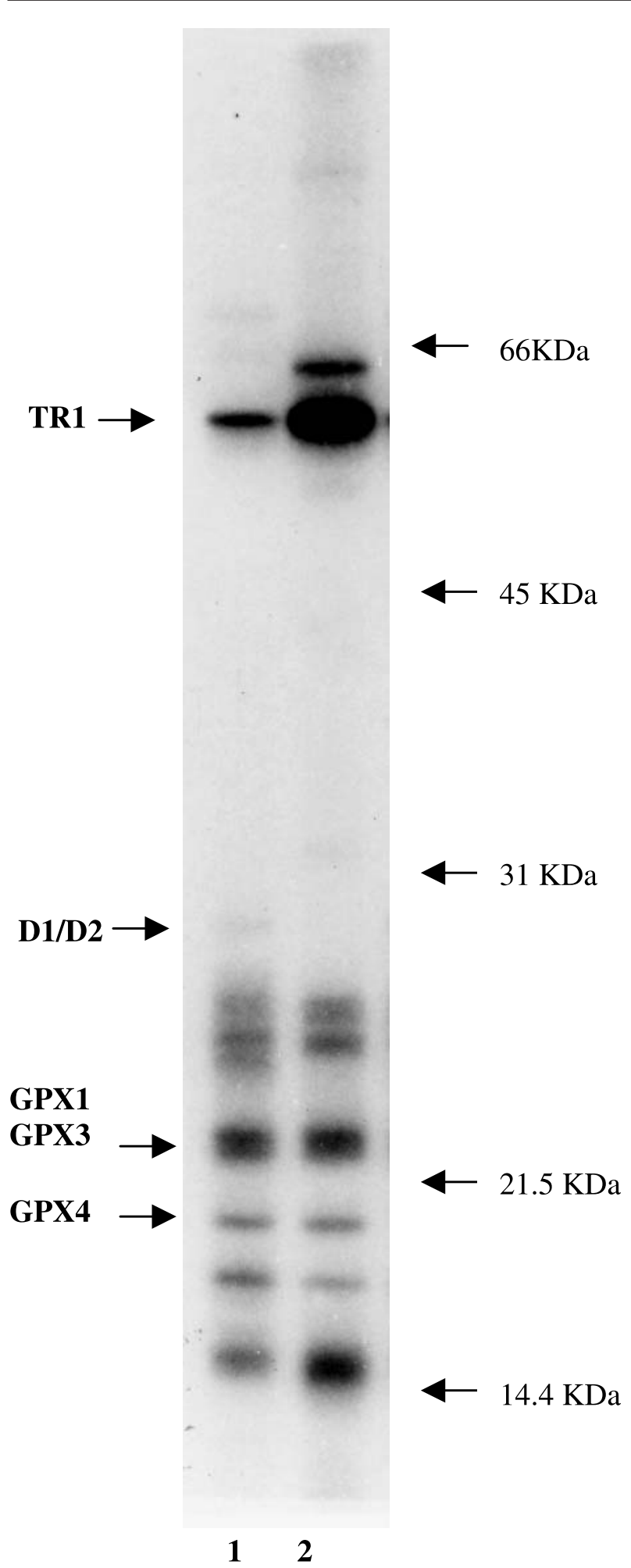

Figure 2 Selenoproteins in human thyrocytes. Autoradiograph of an SDS/PAGE gel taken from sonicates of human thyrocytes grown in the presence of $\left[{ }^{75} \mathrm{Se}\right]$ selenite. Lane 1 , thyrocytes grown in basal medium; lane 2, thyrocytes treated with $10^{-6} \mathrm{M}$ phobol ester (PMA) and the calcium ionophore A23187. adipose tissue. D3 is found in the plasma membrane of brain, placenta and foetal liver and performs only 5-monodeiodination (Fig. 1; Baqui et al. 2003). The biochemistry, cellular and molecular biology and physiological roles of the deiodinases have been reviewed extensively (St Germain 2001, Bianco et al. 2002).

In Se-sufficient rats, hepatic D1 provides an important source of circulating T3 yet in Se-deficient animals, when hepatic D1 expression falls to approximately $10 \%$ of that in Se-adequate animals, plasma T3 concentrations are largely maintained. The maintenance of plasma T3 in these Se-deficient animals arises from an adaptive response driven by a rise in TSH that in turn signals increased de novo synthesis of $\mathrm{T} 3$ on thyroglobulin and also increased expression of thyroidal D1 that promotes high rates of T4-to-T3 conversion (Beckett et al. 1987, Arthur et al. 1990). In humans, thyroidal D2 may also contibute to maintaining plasma T3 in Se deficiency. The paradoxical increase in thyroidal D1 found in Se-deficient rats is made possible because the gland retains adequate amounts of the trace element in dietary Se deficiency (Bermano et al., 1995). Not all animal species express thyroidal D1 and theoretically those lacking the enzyme may be less able to maintain plasma T3 concentrations in Se deficiency (Beech et al. 1993). Since D2 expression and T3 production are vital for regulating thermogenesis in brown adipose tissue, Se-deficient animals may show impaired production of D2 and uncoupling protein, with poor survival when subjected to a cold stress (Arthur et al. 1991).

\section{Se and iodine deficiency}

In humans, attention has focused on how Se status may modify the effects of iodine deficiency and the pathogenesis of endemic myxoedematous cretinism (reviewed by Corvilain et al. 1993, Arthur et al. 1999, Rundlof \& Arner 2004), a condition associated with severe hypothyroidism, thyroid involution and stunted growth. Some epidemiological studies have suggested that the increased generation of $\mathrm{H}_{2} \mathrm{O}_{2}$ caused by the high TSH associated with iodine deficiency, together with a loss of thyroidal selenoperoxidase activity due to concurrent Se deficiency, produces the marked thyroid atrophy found in myxoedematous cretinism. In contrast, if Se supply is adequate thyroid destruction may be prevented due to the maintenance of thyroidal GPX and TR. The importance of Se in protecting the thyroid from oxidative damage is supported by rodent experiments (Contempre et al. 1995). These animal studies suggest also that myxoedematous cretinism may also result from a Se-deficiency-induced disturbance in the inflammatory response (Contempre et al. 1996). More recent reports have failed to provide convincing support for this hypothesis and the possible roles of other additional factors such as dietary thiocyanates must again be considered (Moreno-Reyes et al. 1998). 


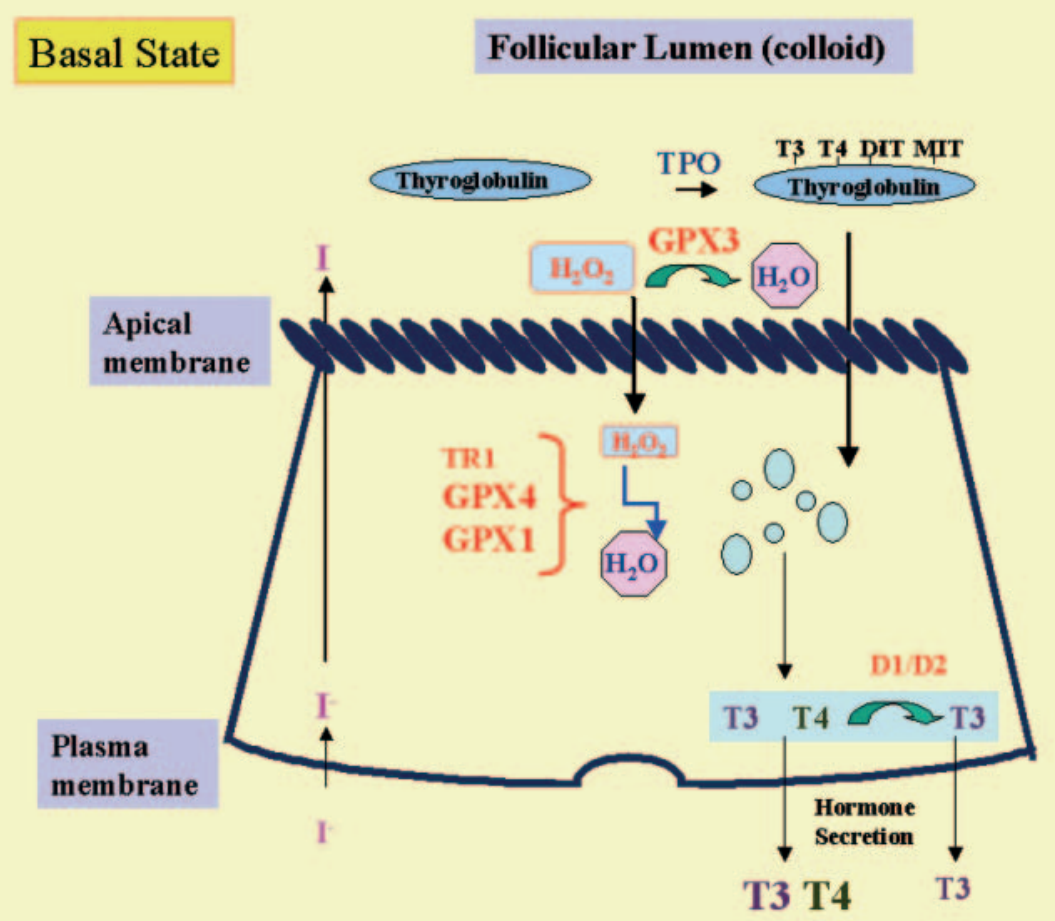

\section{TSH-Stimulated Follicular Lumen (colloid)}

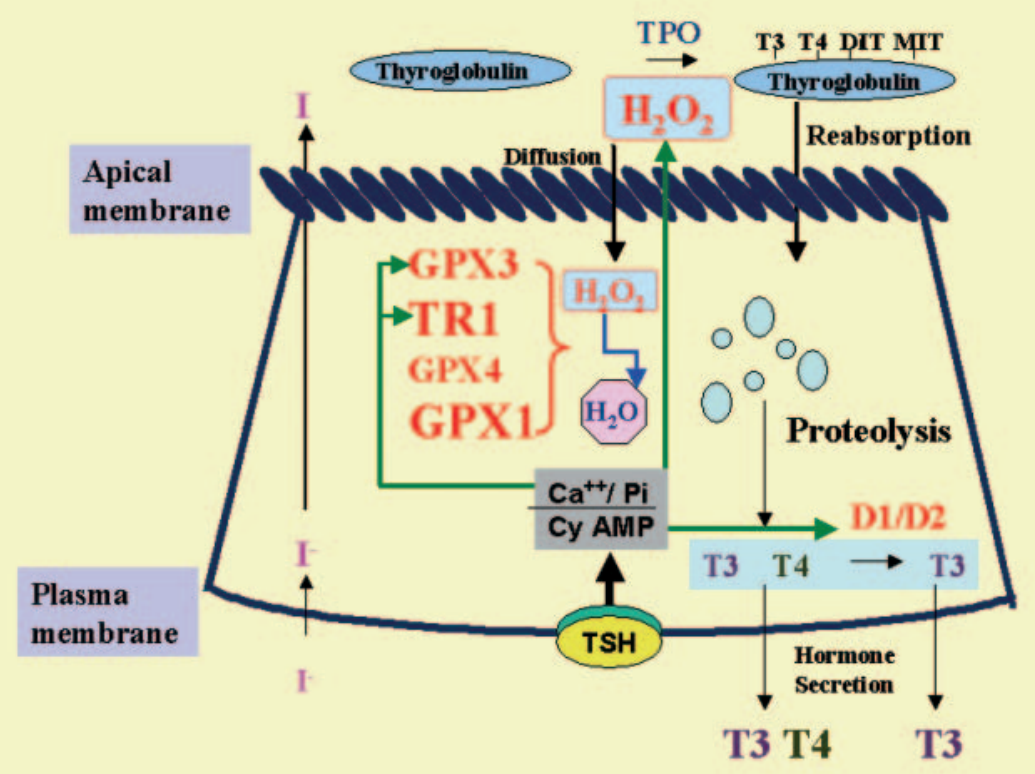




\section{Se and autoimmune thyroid disease}

The links between Se deficiency, altered immune function and inflammation have prompted studies in humans to examine if Se supplementation can modify autoantibody production in patients with chronic autoimmune thyroiditis. Double-blind, randomized, placebo-controlled trials using daily Se supplements of $200 \mu \mathrm{g}$ selenite produced a significant decline in TPO antibody (TPOAb) concentration accompanied in some patients by an improved ultrasound echogenicity of the thyroid (Gartner et al. 2002, Gartner \& Gasnier 2003). This effect of Se on $\mathrm{TPOAb}$ concentration has been demonstrated both in an area of Germany with marginal dietary iodine and Se intakes (Gartner et al. 2002) and in an area around Athens where iodine and Se intakes were close to requirement (Duntas et al. 2003). In these studies Se supplements had no significant effect on the concentration of thyroglobulin antibodies or the concentration of TSH or thyroid hormone concentrations. The mechanism by which Se exerts effects on TPOAb production is likely to be due to the ability of high doses of Se to modify the inflammatory and immune responses (reviewed in (McKenzie et al. 2002a, $2002 b$ ). Further work is required to examine what longterm clinical benefits Se supplementation may have when given to patients with autoimmune thryoiditis. It would be important to determine if Se supplementation could modify the course of Graves' disease since there is one report of Se supplements decreasing the titre of TSH receptor antibodies in such patients ( $\mathrm{Vrca}$ et al. 2004).

\section{Se and fertility}

\section{Se and fertility in males}

The testes contain high concentrations of Se and work with selenoprotein $\mathrm{P}$-knockout mice indicates that $\mathrm{Se}$ is essential for testicular function (Hill et al. 2003). Low sperm production and poor sperm quality including impaired motility with flagella defects localized primarily to the midpiece have been a consistent feature in Sedeficient animals (Watanabe \& Endo 1991, Behne et al. 1996) but it is only relatively recently that an explanation for this phenomenon has been recognized and studies extended to humans (Maiorino et al. 1999, Flohe et al. 2001, Foresta et al. 2002, Maiorino \& Ursini 2002).

GPX4 provides the pivotal link between Se, sperm quality and male fertility since GPX4 is essential to allow the production of the correct architecture of the midpiece of spermatozoa. In testes GPX4 is present as three isoforms that are derived from the same gene and are found in the cytosol, mitochondria and nucleus. The nuclear form differs from the other forms in having an arginine-rich N-terminus (Puglisi et al. 2003, Tramer et al. 2004a, 2004b). In the developing spermatozoa GPX4 probably provides protection from harmful reactive oxygen species but during sperm maturation the selenoenzyme takes on a structural role. In the midpiece of mature sperm GPX4 is a major component present as a polymeric form with no enzymic activity. Thus during sperm development GPX4 first appears in pachytene spermatocyte stages VII-X and its expression gradually increases through the stages of round spermatids with peak levels being found in elongating spermatids. As the spermatozoa mature there is a marked redox switch that is accompanied by an almost complete loss of glutathione. As this occurs reduction of peroxides catalysed by GPX4 in the spermatozoa utilizes protein thiols as an alternative donor substrate to glutathione. This results in GPX4 forming covalent cross-links with itself and other proteins that ultimately build up as a keratin-like material. This material is largely incorporated into the helix of mitochondria in the midpiece of spermatozoa that ultimately forms up to $50 \%$ of the capsule material.

Many human subjects who have infertility due to low sperm count and poor sperm quality have marked decreases in polymerized GPX4 in their sperm. The loss in GPX4 is particularly marked in oligoasthenozoospermic specimens (Foresta et al., 2002). It is unlikely that dietary Se deficiency alone could be the cause since in most patients other pathologies causing infertility could be identified. However, one study performed in Scotland (where Se intakes are below requirements at only 30$40 \mu \mathrm{g} /$ day) showed the sperm quality and fertility of the patients improved after Se supplementation (Scott et al. 1998). Further research is clearly required to determine the association between male fertility in humans

Figure 3 Changes in selenoprotein expression in thyrocytes in the basal state and following stimulation of the TSH receptor. In the TSH-stimulated cells, activation of the $\mathrm{Ca}^{2+} /$ phosphoinositol ( $\mathrm{Pi}$ ) signalling pathways stimulate hydrogen peroxide production and the expression of GPX1 and TR1. In addition the secretion of GPX3 is prevented. These changes provide a large increase in the cells' antioxidant protection systems to prevent peroxidative damage from any hydrogen peroxide that may diffuse into the thyrocyte (see also Fig. 2). The selenoenzymes also detoxify any harmful lipid hydroperoxides. The CAMP (Cy AMP) signalling pathway stimulates the expression of D1 (and D2 in humans but not rats) to promote deiodination of the pro-hormone thyroxine (T4) to the metabolically active hormone tri-iodothyronine (T3). In the basal state GPX3 is actively secreted into the follicular lumen where it will damp-down hormone synthesis by degrading hydrogen peroxide produced in the basal state. In addition, expression of GPX1, TR1 and D1 is diminished in the basal state. The expression of GPX4 is unaltered by TSH stimulation or activation of the $\mathrm{Ca}^{2+} /$ phosphoinositol signalling pathways. MIT, mono-iodotyrosine; DIT, di-iodotyrosine. 
and the range of Se intakes that are seen throughout the world.

\section{Female fertility}

Information regarding the importance of Se in female reproduction is sparse; however, experiments in rodents suggests that Se deficiency has no significant effect on female reproduction even in sixth-generation animals (Bates et al. 2000). In humans a significant depletion of Se in follicular fluid of women with unexplained fertility has been described (Paszkowski et al. 1995). A decrease in the concentration of serum Se occurs throughout normal pregnancy but women with first-trimester miscarriages have significantly lower serum Se concentrations than women in the first trimester whose pregnancies went to term (Barrington et al. 1996). In vitro studies using bovine granulosa cells obtained from different-sized follicles found that Se significantly stimulated the proliferation of cells from small follicles and augmented the stimulatory effects of gonadotrophins in the same cells. Se also enhanced oestradiol production (Basini \& Tamanini 2000). The relevance of these observations to humans is not known.

\section{Se and diabetes}

Se has insulin-mimetic properties in vitro and in vivo. Insulin-stimulated glucose metabolism is impaired in adipocytes isolated from Se-deficient rats (Souness et al. 1983). An insulin-like effect of Se in cultured rat adipocytes include stimulating glucose transport, phosphodiesterase activity and ribosomal S6 protein phosphorylation (Ezaki 1990). When administered to streptozotocindiabetic rats, Se restores glycaemic control and modifies the activity of a range of enzymes involved in hepatic glycolysis and gluconeogenesis. These changes are not linked to changes in insulin levels (McNeill et al. 1991, Ghosh et al. 1994, Becker et al. 1996, Battell et al. 1998, Mukherjee et al. 1998, Ghose et al. 2001). In animal models, Se also prevents or alleviates the adverse effects that diabetes has on cardiac (Battell et al. 1998, Ayaz et al. 2002, 2004), renal and platelet function (Douillet et al. 1996a, 1996b). We are unaware of any publications describing Se-supplementation trials in diabetic humans. Se may exert these insulin-like effects on glucose metabolism by stimulating the tyrosine kinases involved in the distal signalling of the insulin signalling cascade (Pillay \& Makgoba 1992, Stapleton et al. 1997, Hei et al. 1998, McKenzie et al. 2002a).

\section{Conclusions}

The role of Se in the aetiology of several diseases and the impact that Se status has on several endocrine systems has now been established. The multiple roles that selenoproteins play in cell signalling systems and in modifying the immune response, cell growth and cell survival suggest that there are more roles waiting to be discovered for Se in endocrine systems. Se may also have a role in treating malignancies that are responsive to endocrine manipulation. For example Se is effective at reducing the risk of prostatic cancer possibly by inhibiting tumour cell growth via down-regulation of androgen receptor expression (Dong et al. 2003, Dong et al. 2004).

\section{Acknowledgements}

J R A's lab is funded by the Scottish Executive Environment and Rural Affairs Department (SEERAD). The authors declare that there is no conflict of interest that would prejudice the impartiality of this scientific work.

\section{References}

Anema SM, Walker SW, Howie AF, Arthur JR, Nicol F \& Beckett GJ 1999 Thioredoxin reductase is the major selenoprotein expressed in human umbilical-vein endothelial cells and is regulated by protein kinase C. Biochemical Journal 342 111-117.

Arthur JR, Nicol F, Rae PWH \& Beckett GJ 1990 Effect of selenium deficiency on the thyroid gland and plasma and pituitary thyrotrophin and growth hormone concentration in the rat. Clinical Chemistry and Enzyme Communications 3 209-214.

Arthur JR, Nicol F, Beckett GJ \& Trayhurn P 1991 Impairment of iodothyronine $5^{\prime}$-deiodinase activity in brown adipose tissue and its acute stimulation by cold in selenium deficiency. Canadian Journal of Physiology and Pharmacology 69 782-785.

Arthur JR, Beckett GJ \& Mitchell JH 1999 The interactions between selenium and iodine deficiencies in man and animals. Nutrition Research Reviews 12 55-73.

Arthur JR, McKenzie RC \& Beckett GJ 2003 Selenium in the immune system. Journal of Nutrition 133 1457S-1459S.

Ayaz M, Can B, Ozdemir S \& Turan B 2002 Protective effect of selenium treatment on diabetes-induced myocardial structural alterations. Biological Trace Element Research 89 215-226.

Ayaz M, Ozdemir S, Ugur M, Vassort G \& Turan B 2004 Effects of selenium on altered mechanical and electrical cardiac activities of diabetic rat. Archives of Biochemistry and Biophysics 426 83-90.

Baqui M, Botero D, Gereben B, Curcio C, Harney JW, Salvatore D, Sorimachi K, Larsen PR \& Bianco AC 2003 Human type 3 iodothyronine selenodeiodinase is located in the plasma membrane and undergoes rapid internalization to endosomes. Journal of Biological Chemistry 278 1206-1211.

Barrington JW, Lindsay P, James D, Smith S \& Roberts A 1996 Selenium deficiency and miscarriage: a possible link? British Journal of Obstetrics and Gynaecology 103 130-132.

Basini G \& Tamanini C 2000 Selenium stimulates estradiol production in bovine granulosa cells: possible involvement of nitric oxide. Domestic Animal Endocrinology 18 1-17.

Bates JM, Spate VL, Morris JS, St Germain DL \& Galton VA 2000 Effects of selenium deficiency on tissue selenium content, deiodinase activity, and thyroid hormone economy in the rat during development. Endocrinology 141 2490-2500.

Battell ML, Delgatty HL \& McNeill JH 1998 Sodium selenate corrects glucose tolerance and heart function in STZ diabetic rats. Molecular and Cellular Biochemistry 179 27-34. 
Beck MA 2001 Selenium as a antivral agent. In Selenium. Its Molecular Biology and Role in Human Health, pp 235-247. Eds DL Hatfield. Boston: Kluwer Academic Publishers.

Becker DJ, Reul B, Ozcelikay AT, Buchet JP, Henquin JC \& Brichard SM 1996 Oral selenate improves glucose homeostasis and partly reverses abnormal expression of liver glycolytic and gluconeogenic enzymes in diabetic rats. Diabetologia 39 3-11.

Becker K, Gromer S, Schirmer RH \& Muller S 2000 Thioredoxin reductase as a pathophysiological factor and drug target. European Journal of Biochemistry 267 6118-6125.

Beckett GJ, Beddows SE, Morrice PC, Nicol F \& Arthur JR 1987 Inhibition of hepatic deiodination of thyroxine is caused by selenium deficiency in rats. Biochemical Journal 248 443-447.

Beckett GJ, Arthur JR, Miller SM \& McKenzie RC 2004 Minerals and Immune responses-selenium. In Diet and Human Immune Function, pp 217-240, Eds DA Hughes, LG Darlington, A Bendich \& WR Beisel. Totowa, NJ: Humana Press.

Beech SG, Walker SW, Dorrance AM, Arthur JR, Nicol F, Lee D \& Beckett GJ 1993 The role of thyroidal type-I iodothyronine deiodinase in tri-iodothyronine production by human and sheep thyrocytes in primary culture. Journal of Endocrinology 136 361-370.

Beech SG, Walker SW, Arthur JR, Lee D \& Beckett GJ 1995 Differential control of type-I iodothyronine deiodinase expression by the activation of the cyclic AMP and phosphoinositol signalling pathways in cultured human thyrocytes. Journal of Molecular Endocrinology 14 171-177.

Behne D, Hilmert H, Scheid S, Gessner H \& Elger W 1988 Evidence for specific selenium target tissues and new biologically important selenoproteins. Biochimica et Biophysica Acta 966 12-21.

Behne D, Weiler H \& Kyriakopoulos A 1996 Effects of selenium deficiency on testicular morphology and function in rats. Journal of Reproduction and Fertility 106 291-297.

Bermano G, Nicol F, Dyer JA, Sunde RA, Beckett GJ, Arthur JR \& Hesketh JE 1995 Tissue-specific regulation of selenoenzyme gene expression during selenium deficiency in rats. Biochemical Journal $311425-430$.

Bermano G, Nicol F, Dyer JA, Sunde RA, Beckett GJ, Arthur JR \& Hesketh JE 1996 Selenoprotein gene expression during seleniumrepletion of selenium-deficient rats. Biological Trace Element Research 51 211-223.

Bianco AC, Salvatore D, Gereben B, Berry MJ \& Larsen PR 2002 Biochemistry, cellular and molecular biology, and physiological roles of the iodothyronine selenodeiodinases. Endocrine Reviews $\mathbf{2 3}$ 38-89.

Brown KM, Pickard K, Nicol F, Beckett GJ, Duthie GG \& Arthur JR 2000 Effects of organic and inorganic selenium supplementation on selenoenzyme activity in blood lymphoctyes, granulocytes, platelets and erythrocytes. Clinical Science (London) 98 593-599.

Burk RF, Hill KE \& Motley AK 2003 Selenoprotein metabolism and function: evidence for more than one function for selenoprotein P. Journal of Nutrition 133 1517S-1520S.

Callebaut I, Curcio-Morelli C, Mornon JP, Gereben B, Buettner C, Huang S, Castro B, Fonseca TL, Harney JW, Larsen PR et al. 2003 The iodothyronine selenodeiodinases are thioredoxin-fold family proteins containing a glycoside hydrolase clan GH-A-like structure. Journal of Biological Chemistry 278 36887-36896.

Combs GF \& Lu J 2001 Selenium as a cancer preventative agent. In Selenium. Its Molecular Biology and Role in Human Health, pp 205-219. Ed DL Hatfield. Boston: Kluwer Academic Publishers.

Contempre B, Dumont JE, Denef JF \& Many MC 1995 Effects of selenium deficiency on thyroid necrosis, fibrosis and proliferation: a possible role in myxoedematous cretinism. European Journal of Endocrinology 133 99-109.

Contempre B, Le Moine O, Dumont JE, Denef JF \& Many MC 1996 Selenium deficiency and thyroid fibrosis. A key role for macrophages and transforming growth factor beta (TGF-beta). Molecular and Cellular Endocrinology 124 7-15.
Corvilain B, van Sande J, Laurent E \& Dumont JE 1991 The $\mathrm{H}_{2} \mathrm{O}_{2}$-generating system modulates protein iodination and the activity of the pentose phosphate pathway in dog thyroid. Endocrinology 128 779-785.

Corvilain B, Contempre B, Longombe AO, Goyens P, Gervy-Decoster C, Lamy F, Vanderpas JB \& Dumont JE 1993 Selenium and the thyroid: how the relationship was established. American Journal of Clinical Nutrition 57 244S-248S.

Corvilain B, Laurent E, Lecomte M, Vansande J \& Dumont JE 1994 Role of the cyclic adenosine $3^{\prime}, 5^{\prime}$ - monophosphate and the phosphatidylinositol- $\mathrm{Ca}^{2+}$ cascades in mediating the effects of thyrotropin and iodide on hormone synthesis and secretion in human thyroid slices. Journal of Clinical Endocrinology and Metabolism $79152-159$.

Crosley LK, Nicol F, Hesketh JE \& Arthur JR 2003 Differential effects of selenium supply on expression of thioredoxin reductase isoforms in different tissues. Proceedings of the Nutrition Society 62 $71 \mathrm{a}$.

Demelash A, Karlsson JO, Nilsson M \& Bjorkman U 2004 Selenium has a protective role in caspase-3- dependent apoptosis induced by $\mathrm{H}_{2} \mathrm{O}_{2}$ in primary cultured pig thyrocytes. European Journal of Endocrinology 150 841-849.

Dickson RC \& Tomlinson RH 1967 Selenium in blood and human tissues. Clinica Chimica Acta 16 311-321.

Dong Y, Zhang H, Hawthorn L, Ganther HE \& Ip C 2003 Delineation of the molecular basis for selenium-induced growth arrest in human prostate cancer cells by oligonucleotide array. Cancer Research 63 52-59.

Dong Y, Lee SO, Zhang H, Marshall J, Gao AC \& Ip C 2004 Prostate specific antigen expression is down-regulated by selenium through disruption of androgen receptor signaling. Cancer Research 64 19-22.

Douillet C, Bost M, Accominotti M, Borson-Chazot F \& Ciavatti M 1996a In vitro and in vivo effects of selenium and selenium with vitamin $\mathrm{E}$ on platelet functions in diabetic rats relationship to platelet sorbitol and fatty acid distribution. Biological Trace Element Research 55 263-277.

Douillet C, Tabib A, Bost M, Accominotti M, Borson-Chazot F \& Ciavatti M 1996b A selenium supplement associated or not with vitamin E delays early renal lesions in experimental diabetes in rats. Proceedings of the Society of Experimental Biology and Medicine 211 323-331.

Duntas LH, Mantzou E \& Koutras DA 2003 Effects of a six month treatment with selenomethionine in patients with autoimmune thyroiditis. European Journal of Endocrinology 148 389-393.

Ekholm R \& Bjorkman U 1997 Glutathione peroxidase degrades intracellular hydrogen peroxide and thereby inhibits intracellular protein iodination in thyroid epithelium. Endocrinology 138 2871-2878.

Ezaki O 1990 The insulin-like effects of selenate in rat adipocytes. Journal of Biological Chemistry 265 1124-1128.

Flohe L, Brigelius-Flohe R, Maiorino M, Roveri A, Wissing JB \& Ursini F 2001 Selenium and male reproduction. In Selenium. Its Molecular Biology and Role in Human Health, pp 273-281. Ed DL Hatfield. Boston: Kluwer Academic Publishers.

Foresta C, Flohe L, Garolla A, Roveri A, Ursini F \& Maiorino M 2002 Male fertility is linked to the selenoprotein phospholipid hydroperoxide glutathione peroxidase. Biology of Reproduction 67 967-971.

Gartner R \& Gasnier BC 2003 Selenium in the treatment of autoimmune thyroiditis. Biofactors 19 165-170.

Gartner R, Gasnier BC, Dietrich JW, Krebs B \& Angstwurm MW 2002 Selenium supplementation in patients with autoimmune thyroiditis decreases thyroid peroxidase antibodies concentrations. Journal of Clinical Endocrinology and Metabolism 87 1687-1691.

Ghose A, Fleming J \& Harrison PR 2001 Selenium and signal transduction: roads to cell death and anti-tumour activity. Biofactors 14 127-133. 
Ghosh R, Mukherjee B \& Chatterjee M 1994 A novel effect of selenium on streptozotocin-induced diabetic mice. Diabetes Research 25 165-171.

Gromer S, Urig S \& Becker K 2004 The thioredoxin system-from science to clinic. Medicinal Research Reviews 24 40-89.

Hei YJ, Farahbakhshian S, Chen X, Battell ML \& McNeill JH 1998 Stimulation of MAP kinase and S6 kinase by vanadium and selenium in rat adipocytes. Molecular and Cellular Biochemistry 178 367-375

Hill KE, Zhou J, McMahan WJ, Motley AK, Atkins JF, Gesteland RF \& Burk RF 2003 Deletion of selenoprotein P alters distribution of selenium in the mouse. Journal of Biological Chemistry 278 13640-13646.

Holmgren A 2001 Selenoproteins of the thioredoxin system. In Selenium. Its Molecular Biology and Role in Human Health, pp 189-205. Ed DL Hatfield. Boston: Kluwer Academic Publishers.

Howie AF, Walker SW, Akesson B, Arthur JR \& Beckett GJ 1995 Thyroidal extracellular glutathione peroxidase: a potential regulator of thyroid-hormone synthesis. Biochemical Journal 308 713-717.

Howie AF, Arthur JR, Nicol F, Walker SW, Beech SG \& Beckett GJ 1998 Identification of a 57- kilodalton selenoprotein in human thyrocytes as thioredoxin reductase and evidence that its expression is regulated through the calcium-phosphoinositol signaling pathway. Journal of Clinical Endocrinology and Metabolism 83 2052- 2058.

Hume R, Richard K, Kaptein E, Stanley EL, Visser TJ \& Coughtrie MW 2001 Thyroid hormone metabolism and the developing human lung. Biology of the Neonate 80 (suppl 1) 18-21.

Imai H \& Nakagawa Y 2003 Biological significance of phospholipid hydroperoxide glutathione peroxidase (PHGPx, GPx4) in mammalian cells. Free Radicals in Biology and Medicine 34 145-169.

Kester MH, Martinez de Mena R, Obregon MJ, Marinkovic D, Howatson A, Visser TJ, Hume R \& Morreale de Escobar G 2004 Iodothyronine levels in the human developing brain: major regulatory roles of iodothyronine deiodinases in different areas. Journal of Clinical Endocrinology and Metabolism 89 3117-3128.

Kimura T, Okajima F, Sho K, Kobayashi I \& Kondo Y 1995 Thyrotropin-induced hydrogen peroxide production in FRTL-5 thyroid cells is mediated not by adenosine $3^{\prime}, 5^{\prime}$-monophosphate, but by $\mathrm{Ca}^{2+}$ signaling followed by phospholipase-A2 activation and potentiated by an adenosine derivative. Endocrinology 136 116-123.

Kryukov GV, Castellano S, Novoselov SV, Lobanov AV, Zehtab O, Guigo R \& Gladyshev VN 2003 Characterization of mammalian selenoproteomes. Science 300 1439-1443.

Maiorino M, Flohe L, Roveri A, Steinert P, Wissing JB \& Ursini F 1999 Selenium and reproduction. Biofactors 10 251-256.

Maiorino M \& Ursini F 2002 Oxidative stress, spermatogenesis and fertility. Biological Chemistry 383 591-597.

McKenzie RC, Arthur JR \& Beckett GJ 2002a Selenium and the regulation of cell signaling, growth, and survival: molecular and mechanistic aspects. Antioxidants \& Redox Signalling 4 339-351.

McKenzie RC, Arthur JR, Miller SM, Rafferty TS \& Beckett GJ $2002 b$ Selenium and immune function. In Nutrition and Immune Function, pp 229-250. Eds PC Calder, CJ Field \& HS Gill. Wallingford: CABI Publishing.

McNeill JH, Delgatty HL \& Battell ML 1991 Insulinlike effects of sodium selenate in streptozocininduced diabetic rats. Diabetes $\mathbf{4 0}$ $1675-1678$.

Moreno-Reyes R, Suetens C, Mathieu F, Begaux F, Zhu D, Rivera MT, Boelaert M, Neve J, Perlmutter N \& Vanderpas J 1998 Kashin-Beck osteoarthropathy in rural Tibet in relation to selenium and iodine status. New England Journal of Medicine 339 1112-1120.

Mostert V, Hill KE \& Burk RF 2003 Loss of activity of the selenoenzyme thioredoxin reductase causes induction of hepatic heme oxygenase-1. FEBS Lett 541 85-88.

Mukherjee B, Anbazhagan S, Roy A, Ghosh R \& Chatterjee M 1998 Novel implications of the potential role of selenium on antioxidant status in streptozotocin-induced diabetic mice. Biomedicine $\mathcal{E}$ Pharmacotherapy $\mathbf{5 2}$ 89-95.
Nomura K, Imai H, Koumura T \& Nakagawa Y 2001 Involvement of mitochondrial phospholipid hydroperoxide glutathione peroxidase as an antiapoptotic factor. Biological Signals and Receptors 10 81-92.

Paszkowski T, Traub AI, Robinson SY \& McMaster D 1995 Selenium dependent glutathione peroxidase activity in human follicular fluid. Clinica Chimica Acta 236 173-180.

Pillay TS \& Makgoba MW 1992 Enhancement of epidermal growth factor (EGF) and insulinstimulated tyrosine phosphorylation of endogenous substrates by sodium selenate. FEBS Lett 308 $38-42$.

Puglisi R, Tramer F, Panfili E, Micali F, Sandri G \& Boitani C 2003 Differential splicing of the phospholipid hydroperoxide glutathione peroxidase gene in diploid and haploid male germ cells in the rat. Biology of Reproduction 68 405-411.

Raspe E, Laurent E, Corvilain B, Verjans B, Erneux C \& Dumont JE 1991 Control of the intracellular $\mathrm{Ca}(2+)$-concentration and the inositol phosphate accumulation in dog thyrocyte primary culture: evidence for different kinetics of $\mathrm{Ca}(2+)$-phosphatidylinositol cascade activation and for involvement in the regulation of $\mathrm{H}_{2} \mathrm{O}_{2}$ production. Journal of Cell Physiology 146 242-250.

Rayman MP 2000 The importance of selenium to human health. Lancet $356233-241$.

Rayman MP 2002 The argument for increasing selenium intake. Proceeding of the Nutrition Society 61 203-215.

Rundlof AK \& Arner ES 2004 Regulation of the mammalian selenoprotein thioredoxin reductase 1 in relation to cellular phenotype, growth, and signaling events. Antioxidants and Redox Signalling 6 41-52.

Saitoh M, Nishitoh H, Fujii M, Takeda K, Tobiume K, Sawada Y, Kawabata M, Miyazono K \& Ichijo H 1998 Mammalian thioredoxin is a direct inhibitor of apoptosis signal-regulating kinase (ASK) 1. EMBO J 17 2596-2606.

Scott R, MacPherson A, Yates RW, Hussain B \& Dixon J 1998 The effect of oral selenium supplementation on human sperm motility. British Journal of Urology 82 76-80.

Souness JE, Stouffer JE \& Chagoya de Sanchez V 1983 The effect of selenium-deficiency on rat fatcell glucose oxidation. Biochemical Journal 214 471-477.

St Germain DL 2001 Selenium,deiodinases and endocrine function. In Selenium. Its Molecular Biology and Role in Human Health, pp 189-205. Ed DL Hatfield. Boston: Kluwer Academic Publishers.

Stapleton SR, Garlock GL, Foellmi-Adams L \& Kletzien RF 1997 Selenium: potent stimulator of tyrosyl phosphorylation and activator of MAP kinase. Biochimica Biophysica Acta 1355 259-269.

Sun QA, Wu Y, Zappacosta F, Jeang KT, Lee BJ, Hatfield DL \& Gladyshev VN 1999 Redox regulation of cell signaling by selenocysteine in mammalian thioredoxin reductases. Journal of Biological Chemistry 274 24522-24530.

Tramer F, Vetere A, Martinelli M, Paroni F, Marsich E, Boitani C, Sandri G \& Panfili E 2004a CREMtau activates a distinct promoter element for the expression of phospholipid hydroperoxide/sperm nucleus glutathione peroxidase gene. Biochemical Journal $\mathbf{3 8 3}$ 179-185

Tramer F, Caponecchia L, Sgro P, Martinelli M, Sandri G, Panfili E, Lenzi A \& Gandini L 2004b Native specific activity of glutathione peroxidase $(\mathrm{GPx}-1)$, phospholipid hydroperoxide glutathione peroxidase (PHGPx) and glutathione reductase (GR) does not differ between normo- and hypomotile human sperm samples. International Journal of Andrology 27 88-93.

Vrca VB, Skreb F, Cepelak I, Romic Z \& Mayer L 2004 Supplementation with antioxidants in the treatment of Graves disease; the effect on glutathione peroxidase activity and concentration of selenium. Clinica Chimica Acta 341 55-63.

Watanabe T \& Endo A 1991 Effects of selenium deficiency on sperm morphology and spermatocyte chromosomes in mice. Mutation Research 262 93-99. 
Zhang J, Svehlikova V, Bao Y, Howie AF, Beckett GJ \& Williamson G 2003 Synergy between sulforaphane and selenium in the induction of thioredoxin reductase 1 requires both transcriptional and translational modulation. Carcinogenesis 24 497-503.
Received 27 August 2004 Accepted 29 October 2004 